\title{
Research on the Perception of Tourism Image of Xinjiang Tianchi Lake Scenic Spot Based on Online Travels
}

\author{
Jiaxiu Guo \\ Tianhua College \\ Shanghai Normal University \\ Shanghai, 201815
}

\author{
Haiyang Yan \\ Tianhua College \\ Shanghai Normal University \\ Shanghai, 201815
}

\begin{abstract}
In order to learn the tourism image of Tianchi Lake scenic spots in tourists' mind and increase the overall attraction of Tianchi Lake scenic spots, this paper analyzes $\mathbf{3 0 0}$ travels from Ctrip website and Mafengwo by adopting ROST CM6 text analysis software based on Tianchi Lake. It concludes that the major new attraction for Tianchi Lake lies in its magnificent natural landscape and mystery and touris ts pay little attention to human landscape. Tourists hold a positive perception toward the overall image of Tianchi Lake scenic spot and have positive emotion. But there are some negative phenomena, such as tickets price, many peddlers selling incenses in scenic spot, inconvenient traffic among different scenic spot, etc. In addition, some reference and experience are also provided for the management of scenic spot.
\end{abstract}

Keywords-online travels, Tianchi Lake, image perception by tourism, text analysis

\section{INTRODUCTION}

Tourism image is a major fact to attract tourists to travel to the destinations and has great impact on the planning and marketing of tourist destinations. Therefore, it is of great significance to study perceptive image of destinations for the development of regional tourism [1].

With the rapid development of information and communication technology, tourists can spread their experiences of travel and perceptions on destinations in their own manner than ever before. We-media such as Weibo and blog and comment module in online travel agency (OTA) are network platforms for tourists to spread this information. Internet word of mouth plays an increasingly important role in daily consumption decision for tourists and $60 \%$ consumers have included it into their search item as information sources for reference[2].

In particular for the product of service in tourism with marked prior experience characteristic, consumers are hard to judge the quality beforehand. Thus, in order to decrease uncertainty and consume risks, people will manage to collect more travel information in planning their travel[3]. And the experience and comments from tourists or travel guide in largescale websites are exactly the important sources for these information[4]. Internet word of mouth is favored by numerous consumers due to its low search cost and abundant products information in the comments by consumers after they experience. But at the same time, the time and effort spent in the selection among massive information and the cost of recognition also increase significantly, which causes troubles for consumers to make consumption decision[5].

Perception study on tourist destinations mainly focuses on the image study on tourist destinations, study on the difference of the time and space perceived by tourists and study on the factors influencing tourists perception from the perspective of tourists[6], among which the image study on tourist destinations is the most important because it affects travel decision-making, tourists' satisfaction and loyalty by influencing tourists' expectation before travel, thus it becomes the basis of other related research, drawing more and more attention from researchers[7]. This paper analyzes the tourism image of destinations through text contents published online such as blogs, comments and travel guide from the perspective of tourists so as to provide suggestions for potential tourists of destinations and reference on marketing and management decision for tourism operators and manager.

\section{THE INTRODUCTION OF TIANCHAN LAKE SCENIC SPOT}

Located in the middle of Bogda Peak in Fukang city of Changji Hui autonomous prefecture in Xinjiang Uygur autonomous region, Tianchi Lake scenic spot is a national scenic area with 5A-rated tourist attraction in China, covering an areas of 160 square kilometers(548 square kilometers of planning area). It has 4 complete vertical natural landscape belt with Tianchi as its center, Shimen to its north, Xuexian to its south, Maya mountain to its west and Dadonggou to its east. It is the rare mountain natural landscape in our country. In 2013, Xinjiang Tianchi Lake scenic spot was added to UNESCO World Heritage list. In June 2015, the myth of the Queen of Mother of the West was included into the fourth batch of representative projects of national intangible cultural heritage in China.

\section{A. Data sources and processing Selection of samples}

\section{1) Selection of samples}

By using search engine to search the key word "travels of Tianchi Lake scenic spot", this paper selects some websites which record text-based travels of Tianchi Lake scenic spot and 
chooses first rank "ctrip" and the largest travels website "mafengwo" from which 300 travels about tourism in Xinjiang from January 1th 2014 to December 31th 2017 are browsed and 100 travels are selected as research samples. The principle to select samples is based on detailed records of the whole travel itinerary, impression and perception. Travels written by those who join the group tour are eliminated, so do those video and picture-based and poetry and lyric-typed travels and those travels that have yet to finish or update.

\section{2) Pre-processing of samples}

The 100 selected travels will be processed in the following manner: 1 . Combing a series of travels written by the same author, for example, combing the first episode of journey of Tianchi Lake in 2015 with the second episode. 2. Deleting some pictures, extracted educational writings and poetries. 3 . transforming the texts of travels in order to guarantee its consistency of expression for the convenience of extracting particular words, for example, "Wu city" is unified as "Urumchi", "toilet" and "latrine" as "bathroom". After processing this information, there are 95 travels in total with over 593,000 words which store as text documents for further analysis.

\section{3) Research method}

This paper adopts the content analysis method which quantify contents in communication in an objective and systematic manner[8]. Rost CM6 functional analysis software is designed and encoded by Sheng Yang professor and his team from Wuhan University. Such software can support statistical analysis of massive words frequency and be equipped with self-defining word list function, which can research text documents. This paper first of all processes combined documents, but many important words are separated due to limited words in the vocabulary built into this software, thus the result of processing is not as good as we expect. Therefore, this paper enlarges self-defining words list, adding the entries such as the place names of Xinjiang (Urumchi, Hemu), scenic spots (Kanas, Tianchi Lake, International Grand Bazaar), tourist infrastructure ( transportation, accommodation, catering), and tourist activities (hike, self-driving).

\section{THE ANALYSIS OF RESEARCH RESULT}

\section{A. Network analysis on key words}

From network analysis on key words from sample travels of Tianchi Lake, the description is involved in words like place names, scenic areas, time, names, etc. in the samples, among which words about place names and time are the most frequent and intense ones and Xinjiang and Urumchi are the most frequent words in the samples of travels. Therefore, there are two distinct trends in semantic network graph: one is that the location of scenic spots is particularly important, especially the major cities near scenic spots as transportation hub which are the only way to Tianchi Lake scenic spot for tourist. It is confirmed that Urumchi, as an important hub of tour dispatch, plays a prominent role in the Xinjiang tourism development from the perspective of tourists perception. The other trend is that the mountainous natural resource like Tianchi Lake is characterized by distinct seasons and short period suitable for travels.

\section{B. Word frequency analysis}

Based on the built word lists corpus, collected data is segmented and processed as shown in TABLE I. By analyzing and summarizing the most commonly-used words, the cognitive image of tourists on Tianchi Lake scenic spot is analyzed from the aspects of overall impression, perception of scenic spot and specific feeling:

TABLE I.

WORD FREQUENCY ANALYSIS

\begin{tabular}{|c|c|c|c|c|c|}
\hline Rank & Word & Frequency & Rank & Word & Frequency \\
\hline 1 & Tianshan and Tianchi & 1135 & 21 & High Mountain & 62 \\
\hline 2 & Tianshan Scenic Spot & 732 & 22 & Travel & 61 \\
\hline 3 & Tianchi Scenic Spot & 723 & 23 & Arrival & 59 \\
\hline 4 & Urumchi & 159 & 24 & Myth & 58 \\
\hline 5 & Xinjiang & 134 & 25 & Spruce & 57 \\
\hline 6 & Kilometers & 109 & 26 & Turpan & 56 \\
\hline 7 & Bogda Peak & 90 & 27 & Snow Peak & 55 \\
\hline 8 & Yao Lake & 90 & 28 & Tourist Attractions & 54 \\
\hline 9 & Time & 80 & 29 & Queen Mother of the West & 54 \\
\hline 10 & Scenery & 77 & 30 & Snow Mountain & 53 \\
\hline 11 & Place & 75 & 31 & Tour Guide & 52 \\
\hline 12 & Commuter Bus & 74 & 32 & Fukang & 51 \\
\hline 13 & Spruce & 73 & 33 & Tourism & 50 \\
\hline 14 & Itinerary & 72 & 34 & Tickets & 49 \\
\hline 15 & Minute & 71 & 35 & Lakes & 48 \\
\hline 16 & Hour & 70 & 36 & Hotel & 47 \\
\hline 17 & Hemu & 67 & 37 & Train & 46 \\
\hline 18 & Kanas & 66 & 38 & Lake Water & 45 \\
\hline 19 & Tourists & 64 & 39 & Uygur & 44 \\
\hline 20 & Nature & 63 & 40 & Park & 43 \\
\hline
\end{tabular}

In the most commonly-used words, such words as "Tianchi Lake", "Urumchi", "Xinjiang" which are the place names and belong to some places rank in the top. This shows that tourists have strong perception on place names. "Tianshan" and "Tianchi" are the most important factors to attract tourists and also the most typical symbols in Tianchi Lake scenic spot. 
"Bogda Peak" and "Yao Lake" are also in the top of the rank. Bogda peak is the highest peak in the east of Tianshan range and Yao Lake is the old name of Tianchi Lake. Other aspects such as "kilometers", 'time" and "inter-zonal vehicle" tourists pay attention to also rank in the top, which means that distance is still an important factor for tourists. Xinjiang region enjoys a vast territory with rugged terrain, thus transportation is the significant bottleneck to restrict the development of tourism which in turn makes tourists pay more attention to the transportation among different scenic spots and time cost. In addition, what the commonly-used words such as "spruce", "nature" and "high mountain" reflect is that most of tourists pay much more attention to natural landscape than human landscape.

\section{Text analysis of semantic network}

Semantic network is a network graph that represents relationship between concepts and semantic relations, consisting of vertices, which represent issues, concepts, nature, actions, states, etc, and edges, which represent semantic relations between all vertices[9]. It is shown in network graph that "Xinjiang", "Tianshan" and "Tianchi" are the most commonly-used three words in sample travels. "Xinjiang" not only has implications as a tourist attraction but also is the first impression on people's mind. The concurrence of commonlyused words such as "Tianshan", 'the myth of Snow Mountain" and "Turpan" is very suitable for the tourist propaganda of Xingjing to the outside world. In the sample travels, there are many words related to "Tianshan", usually describing natural landscape, which objectively reflects that Tianshan is defined as natural scenery in tourists' mind. Some tourist places and place names such as "hotel", "museum", "park", etc. are hardly mentioned by tourists.

\section{Analysis of emotional image}

The writer sorts out affective vocabularies about Tianchi scenic spot and sequences these vocabularies from the highest to the lowest. The data are as follows:

TABLE II. ANALYSIS OF EMOTIONAL IMAGE OF TIANSHAN AND TIANCHI

\begin{tabular}{|c|c|c|c|c|c|}
\hline Sequence & High-Frequency Adjective & Frequency & Sequence & High-Frequency Adjective & Frequency \\
\hline 1 & Mysterious & 198 & 7 & Famous & 77 \\
\hline 2 & Majestic & 176 & 8 & Amazing & 69 \\
\hline 3 & Magnificent & 167 & 9 & Regretful & 30 \\
\hline 4 & Piety & 100 & 10 & Pure & Other \\
\hline 5 & Beautiful & 100 & 11 & 12 & Let Oneself Free \\
\hline 6 & Fascinating & 99 & \multicolumn{2}{|c|}{3} \\
\hline
\end{tabular}

It is shown from TABLE II that "mysterious", "majestic" and "magnificent" are three most commonly-used words for people to describe Tianshan. Tianshan range is 2,500 kilometers long and the natural boundary between Tarim Basin and Junggar Basin, covering the whole Asian continent. It has 4 complete vertical natural landscape belt, the east of which is Tianchi in the middle of Bogda Peak. Meanwhile, it is wellknown for the myth of the Queen Mother of the West. Thus, it is natural to have such words as majestic, magnificent and mysterious, which is also identical with the tourism image of Tianchi Lake. The writer finds from widespread travels about Tianshan that the vocabularies used in travels are the exact same with the people's perception on the tourism image of Tianchi Lake scenic spot.

\section{E. Statistical analysis of emotional tendency}

Besides cognitive image, the tendency of emotional perception is also of great importance because the research on emotional perception can directly reflect tourists' attitude toward the destinations. Positive emotions often lead to higher levels of satisfaction, vice versa. The emotional vocabularies of tourists are analyzed and summarized by adopting emotional analysis method as shown in TABLE III.

TABLE III. ST ATISTICAL RESULT OF AFFECTION SEGMENT ATION

\begin{tabular}{|c|c|c|}
\hline $\begin{array}{c}\text { Emotional Tendency } \\
\text { and Segmentation }\end{array}$ & Number of Comments & Proportion \\
\hline Positive Emotion & 198 items & $73.88 \%$ \\
\hline Neutral Emotion & 20 items & $7.46 \%$ \\
\hline Negative Emotion & 50 items & $18.65 \%$ \\
\hline \multicolumn{2}{|c|}{ Statistical Result of Positive Emotion Segmentation Is As Follows: } \\
\hline General & 85 items & $30.90 \%$ \\
\hline Intermediate & 52 items & $18.90 \%$ \\
\hline Advanced(Above 20) & 66 items & $24.00 \%$ \\
\hline \multicolumn{2}{|c|}{ Statistical Result of Negative Emotion Segmentation Is As Follows: } \\
\hline General & 52 items & $18.90 \%$ \\
\hline Intermediate & 15 items & $5.45 \%$ \\
\hline Advance( Above - 20) & 5 items & $1.81 \%$ \\
\hline
\end{tabular}

\section{CONCLUSION}

Based on the text of online comments from tourists, this research adopts content analysis method to study the factors and structure of image perception of tourists on Tianchi Lake scenic spot, from which the conclusions and enlightenment are drawn: 
(1)The reason why tourists are willing to be exhausted from a long travel to this place is that they are attracted by its magnificent natural scenery or by their piety belief and admiration. The comments mainly focus on tourist attractions, scenic spots, traffic, infrastructure, time, etc. rather than on accommodation and entertainment, which reflects the weak infrastructure of Tianchi Lake scenic spot.

(2)With respect to the distribution of word frequency, tourists' memory on Tianchi Lake scenic spot centers on Tianchi, Yaochi and Bogda peak which are the most representative tourist symbols for Tianchi Lake scenic spot. In addition, what the commonly-used words such as "spruce", "nature" and "High Mountain" reflect is that most tourists pay much more attention to natural landscape than human landscape. It still requires continuous thinking for Tianchi Lake scenic spot on how to improve its cultural attraction.

(3)Tourists hold a positive attitude toward the overall image of Tianchi Lake scenic spot with relatively higher proportion of highly positive emotion. The achievements Tianchi Lake scenic spot has made response to the feedback of tourists emotional reaction. But it is worth noting for employees that although passive and negative emotion accounts for small part, negative comments as a result of negative emotion has distinct amplification effect. Effective source management and control should be carried out to solve such problems as ticket price, peddlers selling incenses in scenic spot and inconvenient traffic among different scenic spot reflected by tourists in affective analysis.

\section{REFERENCES}

[1] Xie Fangting, Study on Tourism Perception Image of Regions Around Qinghai Lake Based on Online Text Analysis[J].Inner Mongolia Science Technology and Economy, 2017.01

[2] Smith Aaron. Civic Engagement in the Digital Age [R].Washington D.C.: PEW Research Center, 2013.

[3] Bronner F,Hoog R D. Vacationers and Ewom: Who Posts, and Why, Where, and What? [J]. Journal of Travel Research, 2011(1): 15-26.

[4] Duverger P. Curvilinear Effects of User-generated Content on Hotels' Market Share: a Dynamic Panel-data Analysis [J]. Journal of Travel Research, 2013(4): 465-478.

[5] Mudambi S M,Schuff D. What Makes a Helpful On line Review? Study of Customer Reviews on A mazon.com[J].Mis Quarterly, 2010(1): 185-200.

[6] Wang Yuan, Xu Xin, Feng Xuegang, et al, Research on Tourists' Percieved Image of Ancient Town Using Web Text Mining Methods: A Case Study of Zhujiajiao[J]. Tourism Science, 2013(5):90-99. (In Chinese)

[7] Liang Feng, Tourist Destination Image Perception of Wuxi: A Case Study Based on Web Text Analysis[J]Journal of Wuxi Vocational Institute of Commerce, 2017(2).34-35(In Chinese)

[8] Krippendorff K H. Content Analysis: an Introduction to Its Methodology [M]. [S.l.]: Sage Publications, Inc, 1980: 1-40.

[9] Wang Chao, Luo Keren, Research on the Inclusive Development of Tourism in the Perspective of Internet Public Opinion--Case Study on Tickets Policy of Phoenix Ancient City in Hunan[J]Economic Geography, 2014(1):163-169.(In Chinese) 